\title{
Identification of drought in Dhalai river watershed using MCDM and ANN models
}

\author{
Sainath Aher ${ }^{1,2, *} \mathbb{D}$, Sambhaji Shinde $^{1}$, Shantamoy Guha $^{3}$ and Mrinmoy Majumder ${ }^{4}$ \\ ${ }^{1}$ Department of Geography, Shivaji University, Kolhapur 416004 , India. \\ ${ }^{2}$ Department of Geography, S.N. Arts, D.J.M. Commerce \& B.N.S. Science College, Sangamner 422 605, India. \\ ${ }^{3}$ Discipline of Earth Sciences, Indian Institute of Technology, Gandhinagar 382 424, India. \\ ${ }^{4}$ School of Hydro-Informatics Engineering, National Institute of Technology, Agartala 799 046, India. \\ *Corresponding author.e-mail: saigeo23@gmail.com
}

An innovative approach for drought identification is developed using Multi-Criteria Decision Making $(\mathrm{MCDM})$ and Artificial Neural Network (ANN) models from surveyed drought parameter data around the Dhalai river watershed in Tripura hinterlands, India. Total eight drought parameters, i.e., precipitation, soil moisture, evapotranspiration, vegetation canopy, cropping pattern, temperature, cultivated land, and groundwater level were obtained from expert, literature and cultivator survey. Then, the Analytic Hierarchy Process (AHP) and Analytic Network Process (ANP) were used for weighting of parameters and Drought Index Identification (DII). Field data of weighted parameters in the meso scale Dhalai River watershed were collected and used to train the ANN model. The developed ANN model was used in the same watershed for identification of drought. Results indicate that the Limited-Memory QuasiNewton algorithm was better than the commonly used training method. Results obtained from the ANN model shows the drought index developed from the study area ranges from 0.32 to 0.72 . Overall analysis revealed that, with appropriate training, the ANN model can be used in the areas where the model is calibrated, or other areas where the range of input parameters is similar to the calibrated region for drought identification.

\section{Introduction}

Drought is a hydrological phenomenon where the demand of water exceeds its supply from few favourable sources for a considerable time in a specific region (McKee et al. 1993). According to the United States (US) weather bureau, drought is the period of dry weather of sufficient length and severity to cause at least partial crop failure. The India Meteorological Department (IMD) defines drought condition when the rainfall deficiency in any area is more or equal to $26 \%$ of long term normal rainfall (Shewale and Kumar 2005; Kendale 2012). The criteria adopted by Central Water Commission (CWC),
India is followed by the Irrigation Commission in 1972 for drought identification, i.e., drought is a situation when the annual rainfall is less than $75 \%$ of the average in $20 \%$ of the years examined. The major cause of meteorological drought is the occurrence of below normal precipitation, which is affected by various natural phenomena. Most likely causes of occurrence of drought are either decreasing level of precipitation, ground water, vegetation cover or increased evapotranspiration (Kumar 2012). In India, severe drought conditions in most of the river basins are observed in the summer season albeit there is high precipitation with high surface runoff (Van Loon et al. 2014).

Keywords. Multi-criteria decision making; artificial neural network; drought identification. 
Identification of drought at a precise level has drawn considerable attention due to its disastrous effect on society across the world. It is significant for hydrological analysis and water resource management. Monitoring of precise drought areas through field investigation alone is time consuming, costly, and complicated. This problem is scientifically tricky from a hydrological point of view. Normally, drought is quantified based on duration, severity, location in absolute time, areal coverage and the ratio of severity to duration (Dracup et al. 1980). Palmer (1965) has argued that the drought is considered as meteorological phenomena and can be evaluated as a meteorological anomaly characterised by a prolonged and abnormal moisture deficiency. Moreover, in the majority of studies, other parameters like evapotranspiration, streamflow, soil moisture, vegetation canopy, and groundwater data were generally used for drought identification. Usually in drought identification, hydrologic variables, such as annual and monthly precipitation, canopy cover, soil moisture, temperature, evapotranspiration, stream flows have been extensively modelled using linear techniques, such as autoregressive moving average with exogenous inputs (Salas et al. 1985).

Advance Remote Sensing (RS) data derived from Satellite Remote Sensing (SRS) have been used to study the drought situation in large extend area through multiple band data (Aher and Dalvi 2012; Aher et al. 2014). The National Oceanic and Atmospheric Administration (NOAA), which manages operational meteorological satellites, have designed a new Advanced Very High Resolution Radiometer (AVHRR) based Vegetation Condition Index (VCI) which has been shown to be a good tool for drought detection and tracking (Kogan 2008). Similarly, AVHRR satellite data was used for calculating the Normalized Difference Vegetative Index (NDVI) and the Water Supplying Vegetation Index, which are useful indices for the estimation of vegetation health and drought monitoring (Jain et al. 2009). Parida et al. (2013) used the RS-based Soil Moisture Index (SMI), rainfall anomaly data from the Tropical Rainfall Measuring Mission (TRMM), and rice production data for drought detection and validation. In addition to these $250 \mathrm{~m}$, NDVI dataset from Moderate-resolution Imaging Spectroradiometer (MODIS) dataset has opened a new avenue of the identification and prediction of drought (Wan et al. 2004; Zhao and Running 2010). Practitioners have generally accepted these methods during the past several decades. Thus, in drought identification method, the threshold levels of considered factors are needed to be determined.

The use of Multi-Criteria Decision Making (MCDM) and Artificial Neural Network (ANN) model is increased due to its decision making capacity through quantitative manner. Two of the most significant methods of MCDM are Analytic Hierarchy Process (AHP) and Analytic Network Process (ANP). The AHP method proposed by Saaty (1980) for solving socio-economic decision making problems. AHP is utilized when dimensions are independent, and is suited to solve the problems involving dependent dimensions (Yang et al. 2008; Zolekar and Bhagat 2015), while ANP also proposed by Saaty (1996) provides a method for input judgment and measurement to derive ratio scale priorities for the distribution of influence between the different parameters. It was subsequently used for generation of the multi-level hierarchical structure of objectives, criteria, sub-criteria and alternatives (Evangelos and Stuart 1995). In many industrial engineering applications, the final decision is based on an evaluation of a number of alternatives in terms of a number of criteria. This problem may become very difficult when the criteria are expressed in different units or the pertinent data are difficult to be quantified. In drought study, it is necessary for hydrologists to consider alternative models when nonlinearities are important and play a significant role.

The ANN is an alternate computational approach inspired by studies of the brain and nervous systems (McCulloch and Pitts 1943). The main theme of ANN research focuses on modelling of the brain as a parallel computational device for various computational tasks that were performed poorly by traditional serial computers. The ANN model is powerful prediction tool for the relation between drought and its parameters. Moreover, the ANN models have been used increasingly in various aspects of science and engineering because of its ability to model both linear and nonlinear systems without the need to make some assumptions as are implicit in most traditional statistical approaches (Riad and Mania 2004). ANN models are nonlinear mathematical structures that have the ability to show the nonlinearity in the process for communication between inputs and outputs of any system (Hsu et al. 1995). It works with software for searching the best network algorithm to predict the results with synthesis and recognition, adaptive interfaces among parameters data for the index prediction. ANN has shown great ability in modelling and forecasting nonlinear and non-stationary data in hydrology and water resources engineering due to their innate nonlinear property and flexibility for modelling (Dawson and Wilby 2001). Desalegn and Babel (2011) have developed a nonlinear stream flow forecasting model using ANN model at the Awash River, Ethiopia. ANN provides a comprehensive and rational framework to define the structure of a decision problem, to represent 
and quantify its parameters chosen for the study and to evaluate alternative solutions (Saaty and Peniwati 2013).

In view of these, in this attempt, MCDM and ANN models are used for drought-prone region identify along with an advance Drought Index Identification (DII) in the upper Dhalai river watershed in Tripura. The objective of this attempt was to develop a methodology for drought prone region identification using MCDM and ANN models from surveyed drought parameters. In this area, use of MCDM and ANN model was carried out first and reported for drought identification and its validation. Developed methodology is an innovative quantitative approach for precise drought identification in the areas where the model is calibrated or other areas where the range of input parameters are similar to the calibrated region.

\section{The study area}

The north-eastern region of the Indian subcontinent is rich in natural resources. Geologically, this region is underlain by unconsolidated sand, gravel, sandstone, conglomerate, and fractured limestone, which does not support to retain runoff as surface water. Thus, the water holding capacity is not enough in sub-surface layer (Kendale 2012). In this region there is also increasing levels of urbanisation and changes in land use/cover pattern. Therefore, the water retention capacities of the most of the watersheds in these areas are decreasing. Similarly, there is a prevalent state of changes in climatic characteristics during the last few decades and its impact was profound. The Dhalai river (or Dhala river) is sharing the considerable length of the common boundary between India and Bangladesh. It rises in the mountains of Tripura in large, dense forest and enters Kulaura Upazila of Maulvi Bazar District of Bangladesh. The study area covers $550 \mathrm{~km}^{2}$. The north-south and eastwest areal extent are around 37 and $15 \mathrm{~km}$, respectively (figure 1). The general slope is from the south to the north direction, with an average of $7.5^{\circ}$. In the eastern and western directions, having linear-shaped hills, have an average of 350-400 m elevated from mean sea level. Numerous streams and rivulets that originate from the neighbouring hills debouch into the Dhalai river (figure 2). The terrain is dissected by a hilly topography with patches of the plain region formed by deposition of sediment, and exhibit a wide array of sedimentary rocks characteristics of marine-mixed-fluvial type origin (Ghosh et al. 2013). These sediments were deposited in the Surma basin during the late Cenozoic time in a wide range of environmental conditions governed by the local tectonic movement (SER 2002). Such geological formation is influencing the sub-surface groundwater holding capacity of the local region. The whole basin is mainly composed of weathered sandstone, shale, siltstone and alluviums (Ghosh et al. 2013) (figure 3). The average annual rainfall is around 3000-4000 $\mathrm{mm}$, though most part of the upper Dhalai faces the water scarcity problem in summer seasons due to intense runoff and percolation during monsoon.

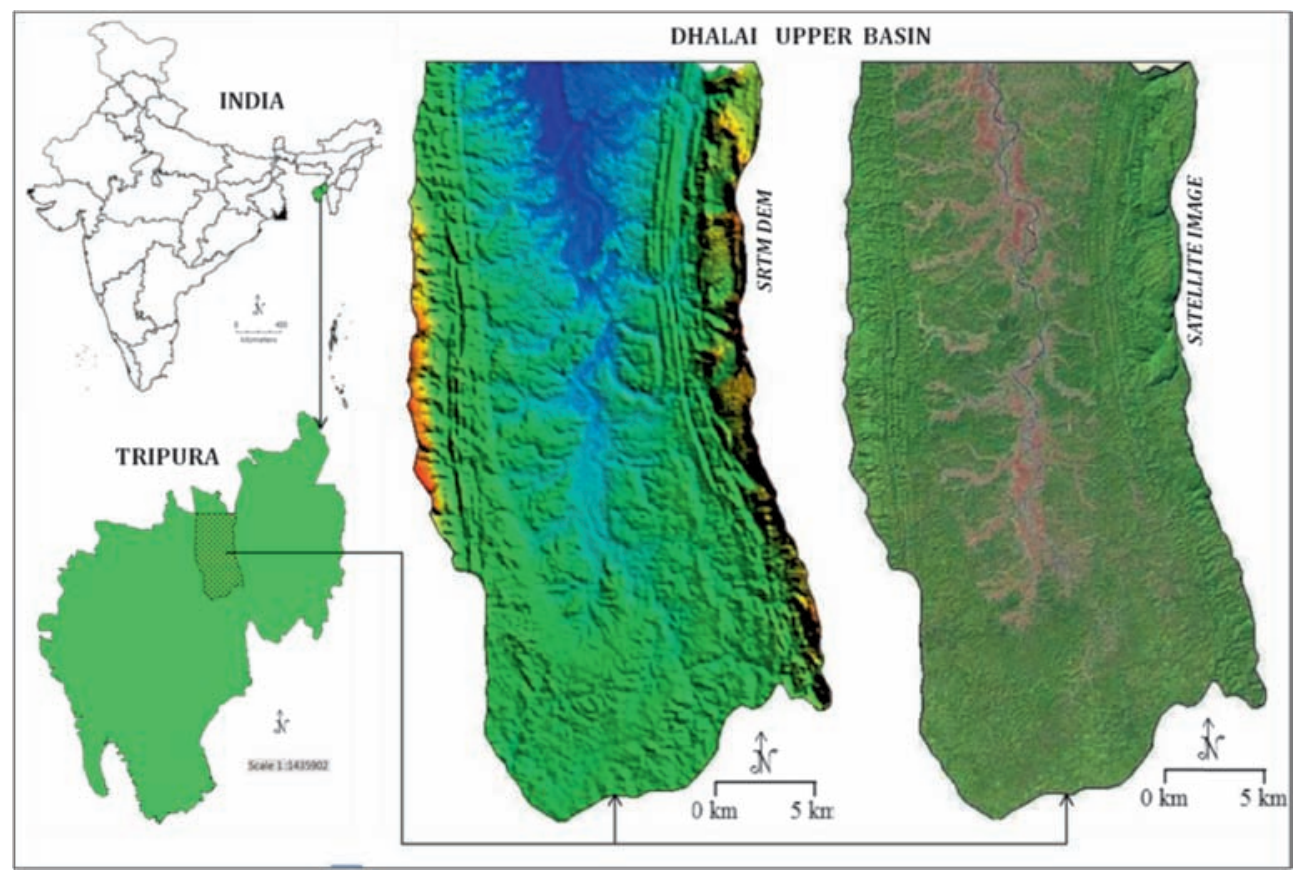

Figure 1. Location map of the upper Dhalai river basin. 


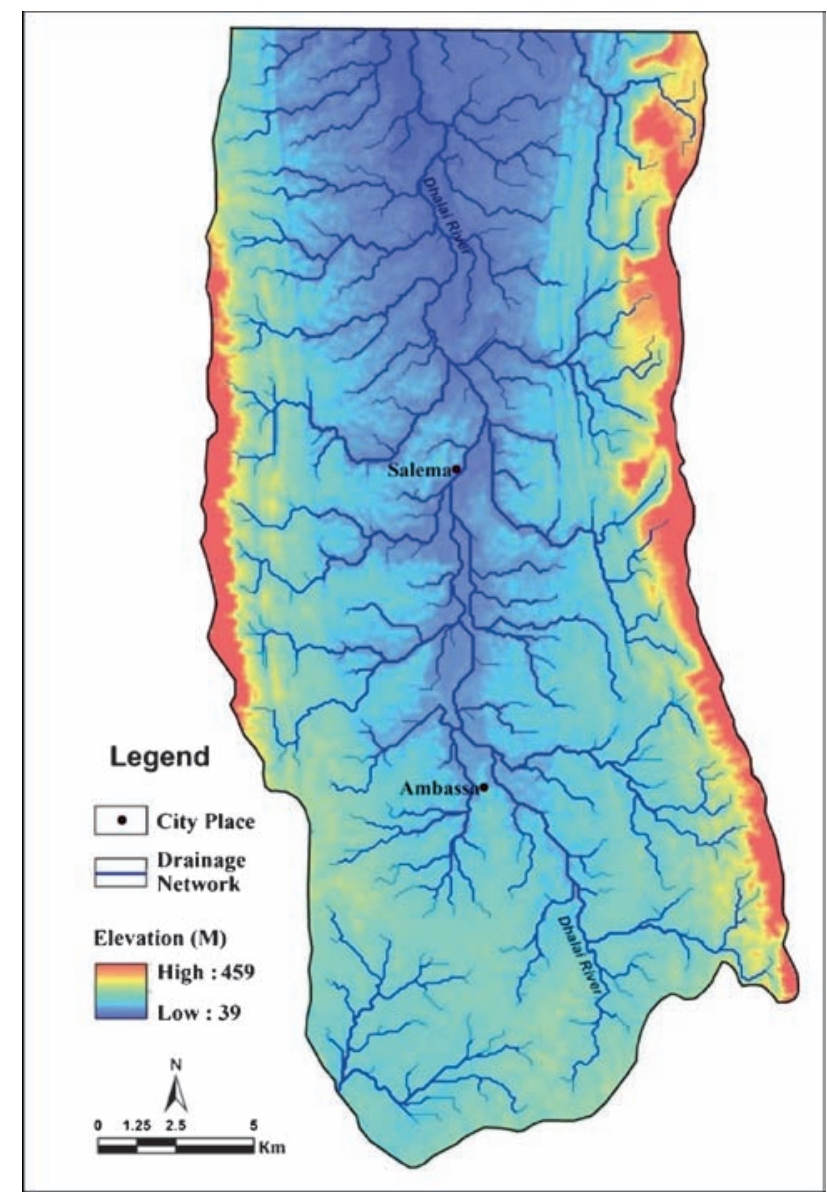

Figure 2. Dhalai river along with tributaries draped over a digital elevation model.

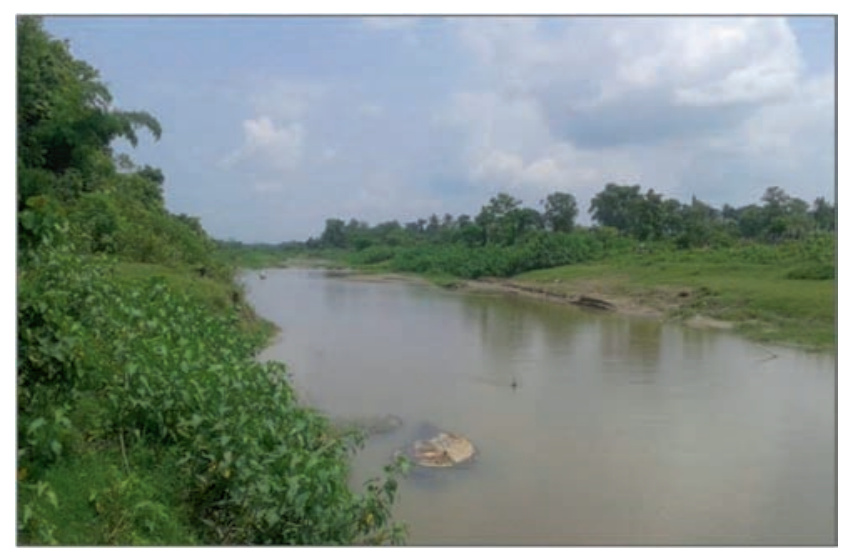

Figure 3. An alluvial reach of Dhalai river near Kulai locality (July 2014).

\section{Materials and methods}

\subsection{Drought parameter identification and ranking}

Parameters associated with drought were collected from expert, literature, and cultivator survey. A total of 50 experts' (researchers) surveys were carried out to identify significant drought parameters. Suggested parameters from experts were ranked according to their relative weight calculated using equation (1).

$$
S_{E}=\frac{A \times\left(a_{m} / a_{t}\right)}{A_{t}},
$$

where $S_{E}$ is the parameters score for the expert survey, $A$ is the number of experts who have suggested this parameter, $a_{m}$ is assigned as most important parameters, $a_{t}$ is assigned as least important parameters and $A_{t}$ is total surveyed experts.

Literature survey was carried out from a total of 50 articles linked to drought (Palmer 1965; Dracup et al. 1980; McKee et al. 1993; Wan et al. 2004; Shewale and Kumar 2005; Jain et al. 2009; Zhao and Running 2010; Kendale 2012; Ghosh et al. 2013; Parida et al. 2013). Parameters accountable for drought were identified from the literature. Identified parameters were ranked according to their relative weight calculated from equation (2).

$$
S_{L}=\frac{l}{L},
$$

where $S_{L}$ is the parameters score for literature survey, $l$ is the number of articles in literature included this parameter and $L$ is the total number of surveyed articles in the literature.

Cultivator survey was also carried out from total 12 cultivators, considering that cultivators have huge experience of drought in the local study area. IRRI (2016) stated that thousands of farmers in the drought-prone Tripura province welcomed the release of 16 new varieties of various crops, including nine rice varieties for different ecosystems. These ecosystems include drought-prone lowlands and uplands. The parameters suggested by cultivators were also ranked according to their relative weight calculated from equation (3).

$$
S_{c}=\frac{c}{C},
$$

where $S_{c}$ is the parameter's score for cultivators' survey, $c$ is the number of cultivators that suggested this parameter and $C$ is the total number of cultivators surveyed.

Identified drought parameters from expert, literature and cultivator survey were used for relative weighting. The ranks were allowed to select the parameters according to their relative weight using equation (4) and the top eight weighted parameters were selected.

$$
S_{A}=\frac{C 1+C 2+C 3}{3},
$$

where $S_{A}$ is an alternative (parameter) score, $C 1$ is a score of the parameter in 1st criterion (expert), 
$C 2$ is a score of the parameter in 2nd criterion (literature) and $C 3$ is a score of the parameter in 3rd criterion (cultivator).

\subsection{Use of MCDM model}

Selected experts', literature and cultivators' criteria were ranked for AHP and ANP and implementation of MCDM. Weight of expert $(E)$ criteria using equation (5), weight of literature $(L)$ criteria using equation (6) and weight of cultivators $(C)$ criteria using equation (7) was calculated and were assigned the relative ranks.

$$
E=\frac{E}{E+L+C}=\frac{50}{50+40+12}=0.49 \quad(\operatorname{Rank} 1)
$$

$$
L=\frac{L}{E+L+C}=\frac{40}{50+40+12}=0.39 \quad(\operatorname{Rank} 2)
$$

$$
C=\frac{C}{E+L+C}=\frac{12}{50+40+12}=0.11
$$

Pairwise comparison matrix (PCM) was then prepared from these three main criterion weights. From the obtained weight of three criteria, geometric mean was calculated (table 1 ). Then, the supermatrix was prepared from the PCM. The weights

Table 1. Pair-wise comparison matrix (PCM) for criteria.

\begin{tabular}{cccccc}
\hline & & & & Geometric & \\
& $\mathrm{E}$ & $\mathrm{L}$ & $\mathrm{C}$ & mean & Normalization \\
\hline $\mathrm{E}$ & $1 / 1$ & $2 / 1$ & $3 / 1$ & 1.82 & 0.2577 \\
$\mathrm{~L}$ & $1 / 2$ & $1 / 1$ & $3 / 2$ & 0.91 & 0.0322 \\
$\mathrm{C}$ & $1 / 3$ & $2 / 3$ & $1 / 1$ & 0.61 & 0.0094 \\
\hline
\end{tabular}

of all the parameters were multiplied with each criteria weight (weight of criteria $(\mathrm{PCMs}) \times$ weight of parameters) in AHP. A similar process was carried out in ANP. Validation of supermatrix was carried out through normalisation of AHP and ANP weights and its summation equal to one (table 2).

\subsection{Drought index}

Final weights of drought parameters were calculated from AHP and ANP weight average. Similarly, random values were prepared from final weight of parameters in a Microsoft excel sheet. The drought index was generated from final weight of parameters and random values using equation (8) and trained in the ANN model (table 3).

$$
\text { Index }=I A \times I p
$$

where $I A$ is the actual index and $I p$ is the predicted index.

\subsection{Training of ANN model}

Drought index training was computed in Alyuda NeuroIntelligence software for nonlinear ANN model development with seven algorithms: (1) Quick Propagation, (2) Conjugate Gradient Descent, (3) Quasi-Newton, (4) Limited-Memory Quasi-Newton, (5) Levenberg Marquardt, (6) Online Back Propagation, and (7) Batch Back Propagation for searching the best neural network. The training process of Limited-Memory QuasiNewton algorithm was shown along with multiple steps of testing and query (figure 4).

\subsection{Data collection}

The selected Upper Dhalai Watershed (UDW)

\begin{tabular}{|c|c|c|c|c|c|c|c|c|}
\hline & \multicolumn{3}{|c|}{ Criteria } & & \multirow{2}{*}{$\begin{array}{l}\text { AHP } \\
\text { weight }\end{array}$} & \multirow{2}{*}{$\begin{array}{c}\text { AHP } \\
\text { normalization }\end{array}$} & \multirow{2}{*}{$\begin{array}{l}\text { ANP } \\
\text { weight }\end{array}$} & \multirow{2}{*}{$\begin{array}{c}\text { ANP } \\
\text { normalization }\end{array}$} \\
\hline & $(\mathrm{C} 1)$ & $(\mathrm{C} 2)$ & (C3) & & & & & \\
\hline A1 & 0.3687 & 0.3664 & 0.3729 & AHP weight & 0.11032 & 0.35108 & 0.36981 & 0.32747 \\
\hline $\mathrm{A} 2$ & 0.0921 & 0.1280 & 0.1864 & 0.2577 & 0.02961 & 0.09423 & 0.14226 & 0.12597 \\
\hline A3 & 0.1778 & 0.0916 & 0.0616 & 0.0322 & 0.04935 & 0.15705 & 0.10428 & 0.09234 \\
\hline A4 & 0.1288 & 0.1832 & 0.0932 & 0.0094 & 0.03997 & 0.12719 & 0.12876 & 0.11402 \\
\hline A5 & 0.0737 & 0.0450 & 0.1238 & ANP weight & 0.02161 & 0.06876 & 0.08705 & 0.07709 \\
\hline A6 & 0.0608 & 0.0732 & 0.0745 & 0.2955 & 0.01873 & 0.05959 & 0.07008 & 0.06206 \\
\hline $\mathrm{A} 7$ & 0.0521 & 0.5180 & 0.0410 & 0.2783 & 0.03049 & 0.09704 & 0.17703 & 0.15676 \\
\hline A8 & 0.0457 & 0.0605 & 0.0462 & 0.4261 & 0.01416 & 0.04506 & 0.05003 & 0.0443 \\
\hline & & & & & $=0.31422$ & 1 (Validation) & $=1.1293$ & 1 (Validation) \\
\hline
\end{tabular}
was divided into 66 grids with two interlaced $3.17 \times 3.46 \mathrm{~km}^{2}$ grids for grid-wise data collection.

Table 2. Super matrix of $A H P$ and $A N P$. 
Hydrological and meteorological data for each grid from UDW were collected from various primary and secondary sources. The average precipitation data for the year 2013 were collected from IMD, evapotranspiration and temperature data were collected from online data sources like the Worldclim data (http://www.worldclim.org/), and AccuWeather data (http://www.accuweather. com/en/in/india-weather) for the year 2013. Dhalai district administrative website was also used for cross-verification of precipitation and temperature data. Land use/cover information was extracted from a Landsat image, acquired on December 2013 using Erdas Imagine 9.1 image processing software to know the vegetation canopy, cropping pattern and cultivated land information. Soil moisture data were extracted from 13 soil samples, collected in May 2013 in UDW. Soil moisture (\%) was measured with the help of electronic balance from equation (9).

$$
S_{M}=\frac{x-y}{x} \times 100,
$$

where $S_{M}$ is soil moisture (\%), $x$ is the total weight of soil (wet) and $y$ is the weight of soil (dried).

The obtained soil moisture data from 13 soil samples were interpolated using the kriging method in Surfer software. Kriging is a geostatistical interpolation technique, which estimates unknown values with a specific probabilistic distribution at an arbitrary point of the space (Deshmukh and Aher 2016a, b). Average water table data from the Katalutma, Ambasa, Abhanga, Balaram and Halhuli stations were collected in the year 2011 from central ground water board website. Similar kriging interpolation method was used for groundwater table data interpolation in UDW. Geostatistical interpolation of sampled data using Geographical Information System (GIS) software provides the information or data of unknown area or points within the selected area (Deshmukh and Aher 2014).

\subsection{Drought indexing and identification}

The actual drought index was prepared from experts', literature, and cultivators' survey data with the help of MCDM and ANN models. Meanwhile, the predicted index was also prepared from gridwise collected data of UDW. Collected data of eight parameters for 66 grids of UDW were used for drought index development and its preparation using developed Limited-Memory Quasi-Newton algorithm (neural network). It was better than the commonly used training method because of minimum actual root errors, 0.004863 as 


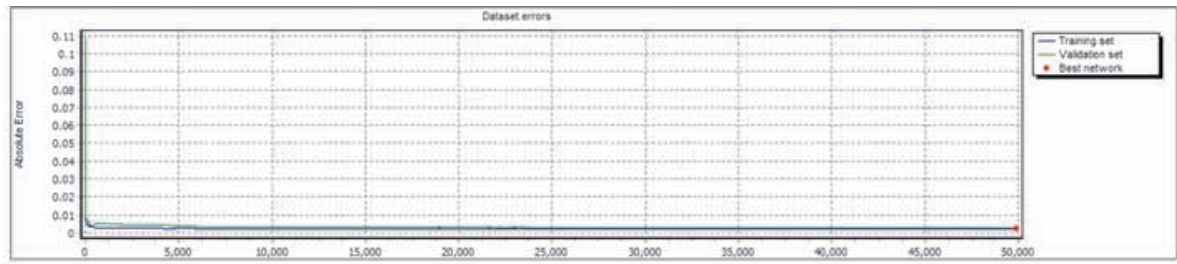

(a)

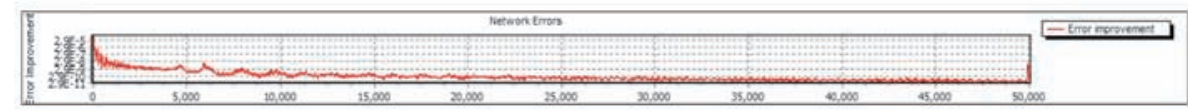

(b)

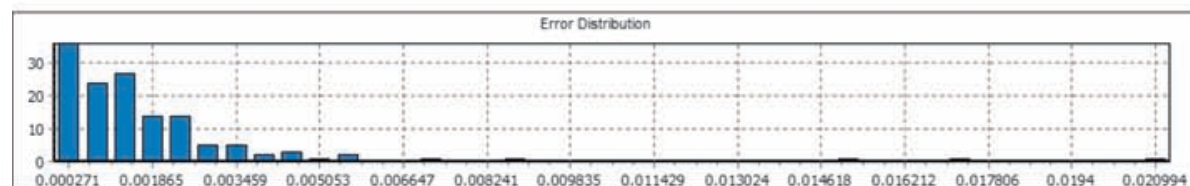

(c)

Testing

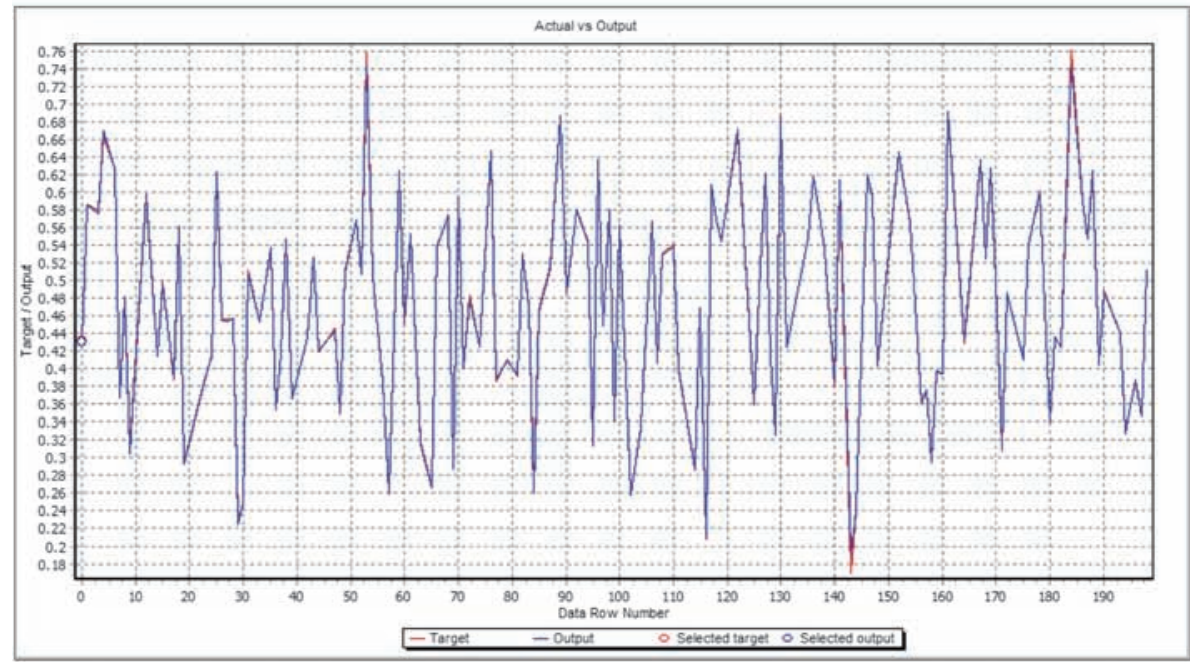

(d)

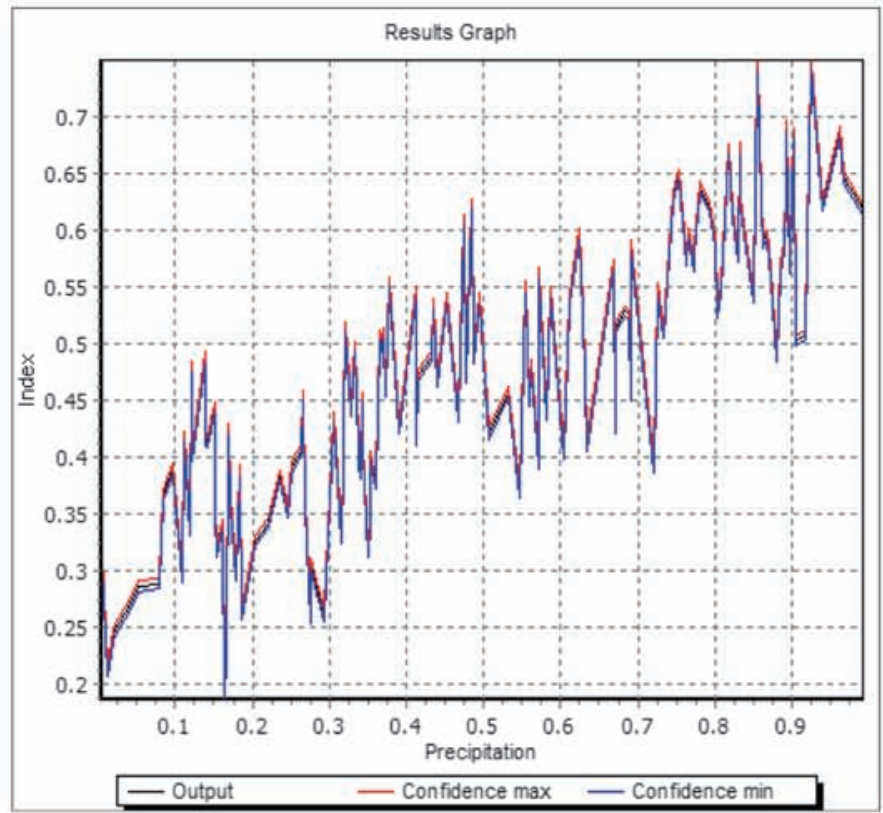

(e)

Figure 4. Detailed hierarchical process in the ANN model. (a) Dataset error, (b) network error, (c) error distribution, (d) actual vs. output and (e) resultant graph. 
compared to other algorithms. Collected parameter data were normalised considering a direct relationship of parameters and drought (maximum temperature-maximum drought), as well as an indirect relationship of parameters and drought (high precipitation-minimum drought) using equation (10).

$$
A_{N}=\frac{\text { Actual }-\operatorname{Min}}{\operatorname{Max}-\operatorname{Min}}
$$

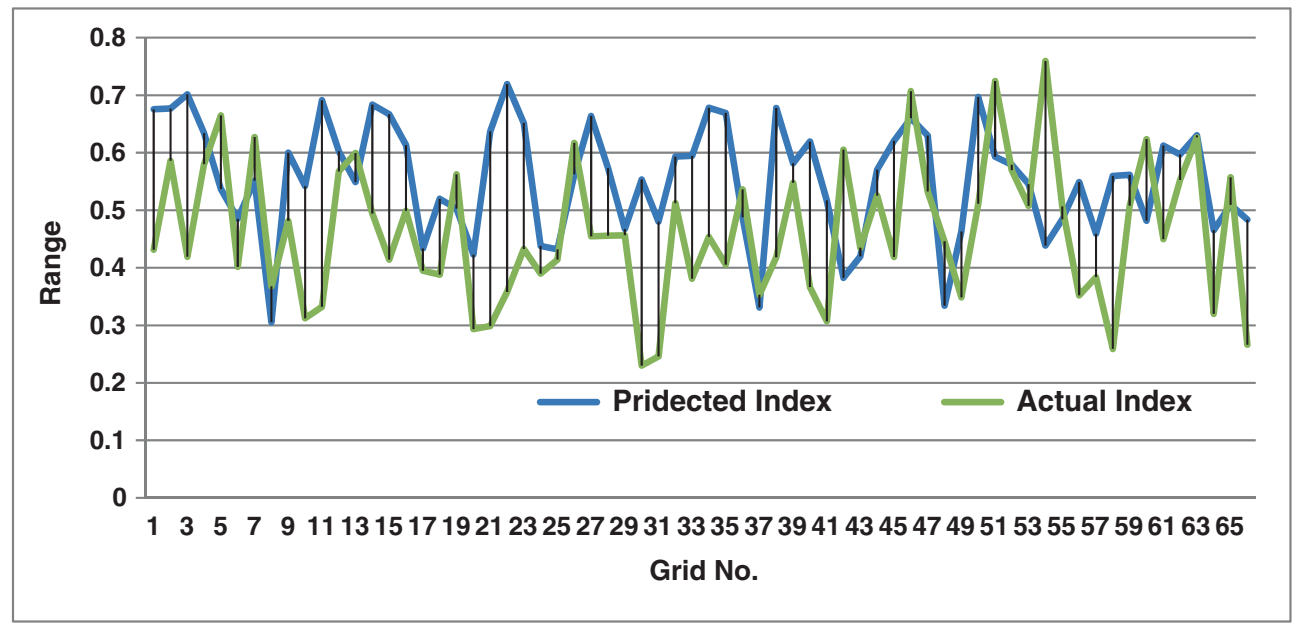

Figure 5. Input (actual) and output (predicted) index.

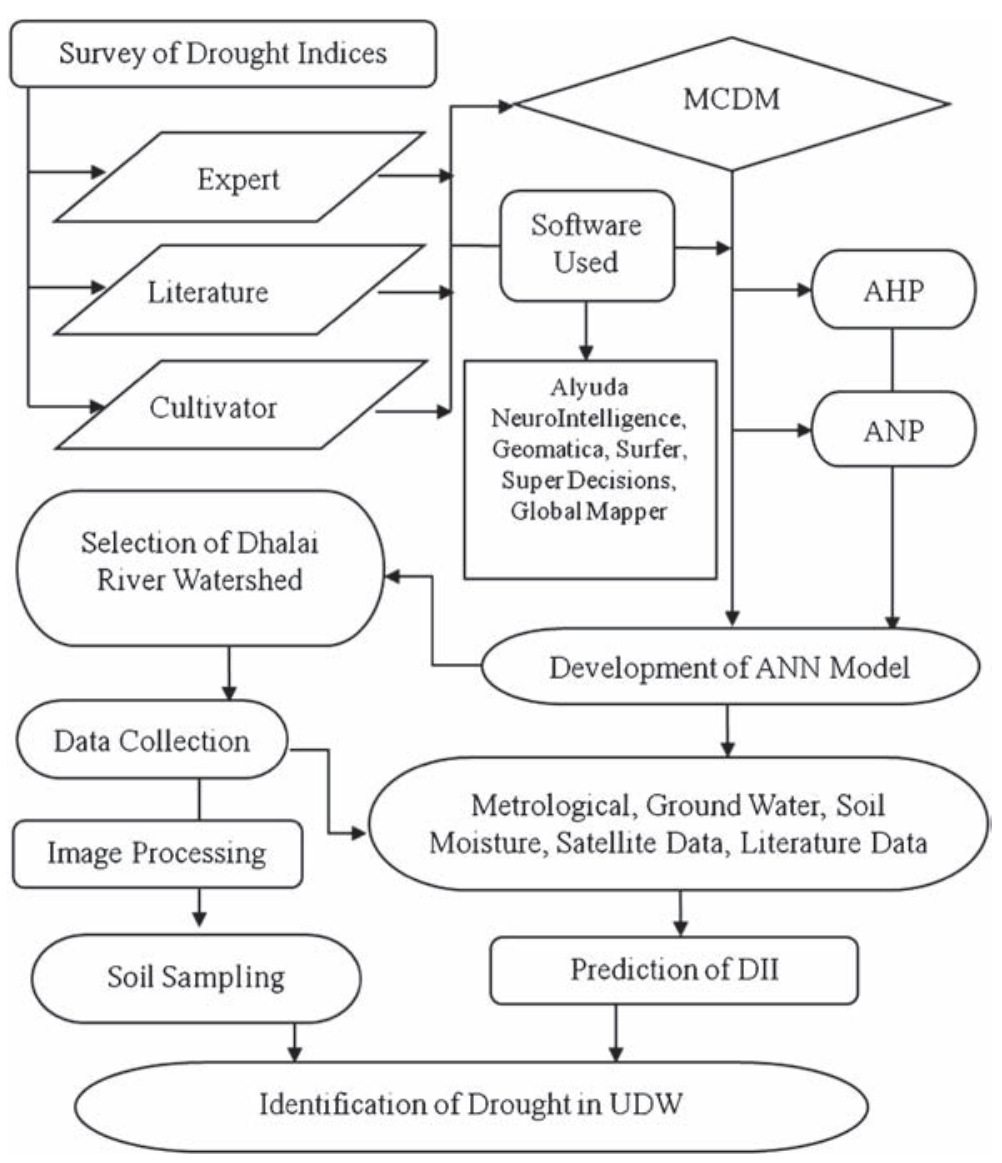

Figure 6. Detailed flow chart of the methodology. 
where $A_{N}$ is the normalised parameter, 'Actual' is the value selected for normalisation, 'Min' is the lower value of parameters in all grids and 'Max' is the maximum value of parameters in all grids.

Developed ANN model, Limited-Memory QuasiNewton algorithm and collected data of UDW were finally used for drought-prone region identification in the UDW study area. Drought index was developed and predicted from collected database from 66 grids in the study area. The actual and predicted drought index was used for drought identification in the selected area (figure 5). Data of all parameters were mosaic in the GIS software for final drought area identification in the UDW study area. Figure 6 shows the detailed flow chart of the methodology.

\section{Results and discussions}

\subsection{Drought parameters and weighted ranking}

From the experts', literature and cultivators' survey, eight significant parameters were obtained and

Table 4. Drought parameters and its weighted ranking.

\begin{tabular}{lllllll}
\hline \multirow{2}{*}{ Sl. no. } & \multicolumn{1}{c}{ Parameter } & \multicolumn{5}{c}{ Score } \\
\cline { 3 - 7 } & Experts & Literature & Cultivator & Average & Rank \\
\hline 1 & Precipitation & 2 & 0.7 & 0.87 & 1.17 & 1 \\
2 & Soil moisture & 0.3 & 0.6 & 0.75 & 0.55 & 2 \\
3 & Evapotranspiration & 0.8 & 0.5 & 0.25 & 0.51 & 3 \\
4 & Vegetation canopy & 0.46 & 0.6 & 0.41 & 0.49 & 4 \\
5 & Cropping pattern & 0.2 & 0.3 & 0.58 & 0.36 & 5 \\
6 & Temperature & 0.13 & 0.5 & 0.33 & 0.32 & 6 \\
7 & Cultivated land & 0.13 & 0.4 & 0.16 & 0.23 & 7 \\
8 & Groundwater level & 0.08 & 0.4 & 0.16 & 0.21 & 8 \\
\hline
\end{tabular}

Table 5. Final weight of parameters.

\begin{tabular}{lcccc}
\hline Parameters & $\begin{array}{c}\text { AHP } \\
\text { weight }\end{array}$ & $\begin{array}{c}\text { ANP } \\
\text { weight }\end{array}$ & $\begin{array}{c}\text { Final } \\
\text { weight }\end{array}$ & Rank \\
\hline Precipitation (A1) & 0.3511 & 0.3109 & 0.3310 & 1 \\
Evapotranspiration (A3) & 0.1570 & 0.1391 & 0.1481 & 2 \\
Vegetation canopy (A4) & 0.1272 & 0.1126 & 0.1199 & 3 \\
Cultivated land (A7) & 0.0970 & 0.0859 & 0.0915 & 4 \\
Soil moisture (A2) & 0.0942 & 0.0834 & 0.0888 & 5 \\
Cropping pattern (A5) & 0.0688 & 0.0609 & 0.0648 & 6 \\
Temperature (A6) & 0.0596 & 0.0528 & 0.0562 & 7 \\
Ground water level (A8) & 0.0451 & 0.0399 & 0.0425 & 8 \\
\hline
\end{tabular}

Table 6. Trained index using algorithms (ANN model).

\begin{tabular}{lllll}
\hline \multirow{2}{*}{ Neural network training } & \multicolumn{4}{c}{ Mean level after index training } \\
\cline { 2 - 5 } Quick propagation & Target & Output & AE & ARE \\
Conjugate gradient descent & 0.4728 & 0.472798 & 0.005921 & 0.014948 \\
Quasi Newton & 0.4728 & 0.472826 & 0.002068 & 0.005365 \\
Limited Memory-Quasi Newton* & 0.4728 & 0.47276 & $0.001909^{*}$ & $0.004863^{*}$ \\
Levenberg Marquardt & 0.4728 & 0.473535 & 0.005149 & 0.012363 \\
Online back propagation & 0.4728 & 0.473247 & 0.008286 & 0.021116 \\
Batch back propagation & 0.4728 & 0.472781 & 0.010027 & 0.025477 \\
\hline
\end{tabular}

AE: actual error, ARE: actual root error, $*$ : Minimum actual error and actual root error. 


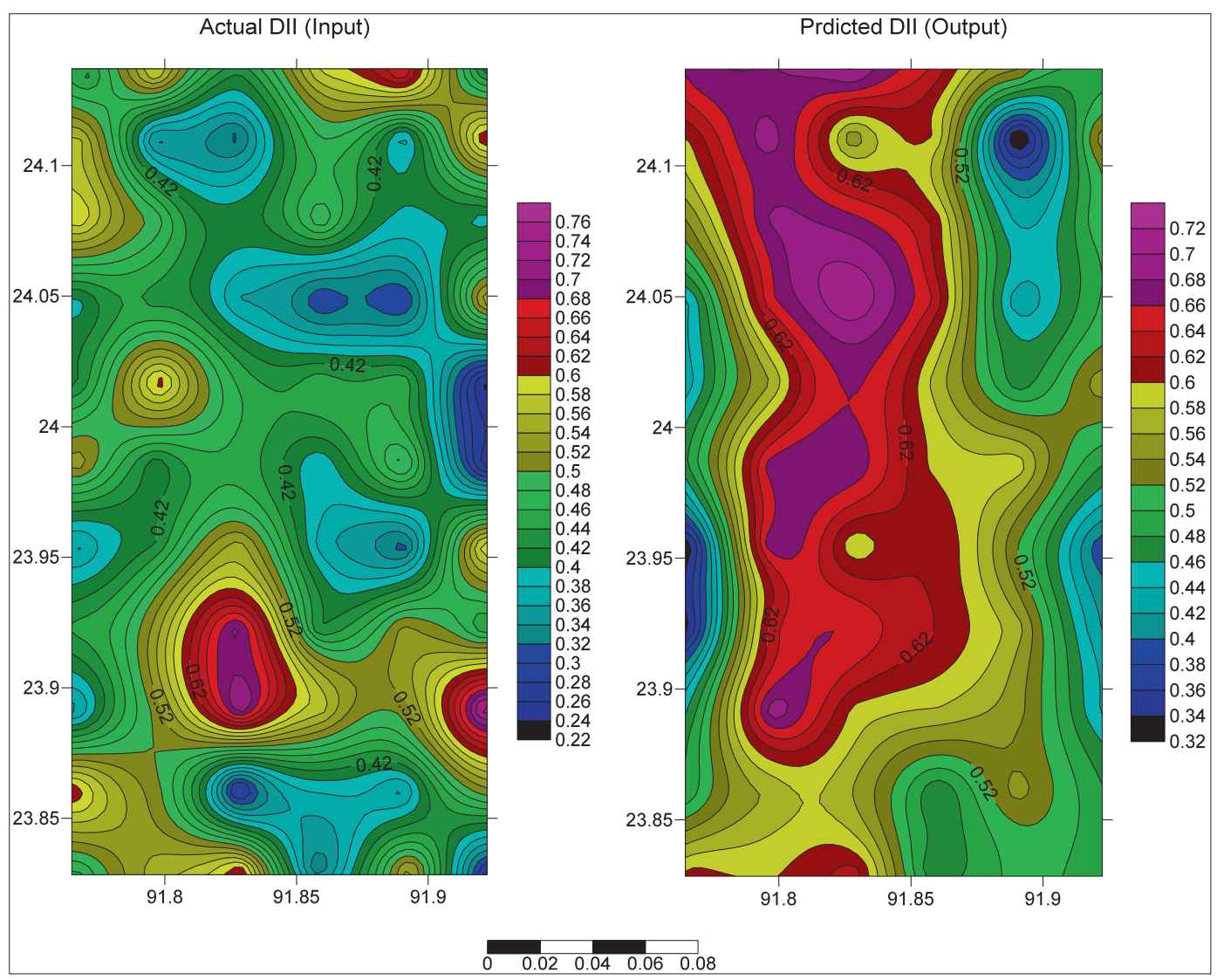

Figure 7. DII using (a) direct method and (b) ANN and MCDM model.

ranked according to the relative weight of parameters. Precipitation significantly correlated with drought, while the ground water level was less correlated with drought, according to revealed weightage (table 4 ).

\subsection{MCDM model}

Selected experts', literature and cultivators' criteria were also ranked for AHP and ANP processes in the MCDM. Ranking of criteria was obtained as expert - 0.49 (rank 01), literature - 0.39 (rank 02), and cultivator -0.11 (rank 03) from the PCM. According to the mean score of the parameter from AHP and ANP, precipitation has the highest score (0.3310), while groundwater level found the lower score (0.0425). Therefore, relative rank to precipitation is first to be considered and then other weighted rank parameters can be taken into account (table 5).

\subsection{ANN model development, testing and validation}

The obtained index from AHP and ANN in supermatrix were trained with different algorithms.
Results obtained from different algorithms training are presented in table 6 . The best neural network was found to be the Limited-Memory Quasi-Newton where the actual error was 0.001909 and actual root error was 0.004863 , which was minimum compared to other trained algorithms (table 6).

Drought index was prepared using a developed ANN model with the best neural network. Parameter data (grid-wise) from UDW were used to compare the actual drought conditions in the study area (Appendix 1). The actual drought index and the predicted drought index were generated after the training and by collecting a database of UDW in the developed limited-memory QuasiNewton network. Based on collected data and use of the limited-memory Quasi-Newton network, actual and predicted drought index were developed. The composite range of indices is $0.22-0.76$ and $0.32-0.72$ for the present study area (figure 7 ). In the actual index, the maximum affected area is identified in the south central part, which is indicated by greater than 0.6 index value, while the minimum drought-affected region is the eastcentral section of the study area. In the predicted index, maximum drought effects were identified in the northern-central section of the watershed, while 


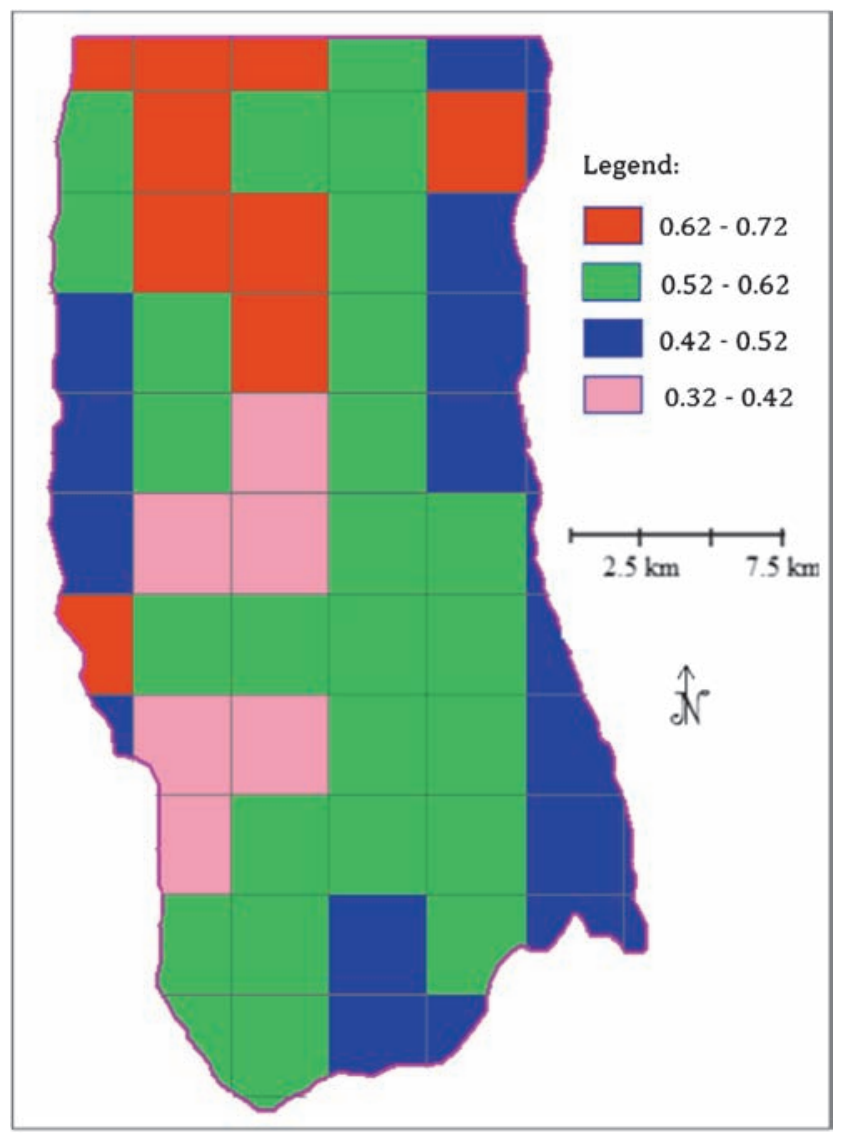

Figure 8. Gridded drought index for the upper Dhalai river basin.

the minimum was found in the east-west marginal boundary UDW (figure 7).

\subsection{Drought identification}

The present area is havocked by several drought phases with variable intensity in overall areas. The prime characteristic of entire collected or gathered drought parameter data is its inherent nonlinearity. The developed Limited-Memory Quasi-Newton algorithm was better than the commonly used training method for drought identification. Based on primary and secondary collected data and the quantitative database from MCDM and ANN models, grid-wise drought-prone regions were identified in UDW of Tripura hinterland (figure 8). It was based on direct relationships, as the maximum index value indicated the maximum intensity of drought, while the minimum index value indicated the minimum intensity of drought. According to this approach, the maximum drought-affected area was identified in the northern part, while relatively minimum droughts in the middle and south-west sections of the UDW study area (figure 8). The grid-wise variations in the drought index value ranging from 0.32 to 0.72 might be due to local topography, slope and nature of the land use and land cover in the present area. It can be argued that near the river channel the intensity of drought is less.

\section{Conclusions}

In this study, an ANN model was developed and trained to identify the grid-wise drought prone area using MCDM model and selected parameter data. Based on eight drought parameters from expert, literature, and cultivator survey, the ANN model was trained. The trained ANN model was tested in the mesoscale upper DRW in Tripura hinterlands, India. The obtained results have depicted that the Limited-Memory Quasi-Newton algorithm was better than the commonly-used training method for these types of area. Results obtained from the ANN model, 0.32 to 0.72 are the drought index that has developed for the present study area (figure 8). It has been generally argued that near the river channel the problem of water scarcity would be less. Using climatic and other data set and subsequently some nonlinear model, it has been observed that the potential zone for the problem of water is near the river channel. Validation with data outside of the upper DRW recommended that the ANN model trained with data from the upper DRW had better predictive potential when there are similar types of input data. Moreover, predictive precision was considerably reduced and recalibration of the ANN model's parameters may be required if the input data were dissimilar. Overall, the analysis revealed that with appropriate training, the ANN model can be used in the areas where the model was calibrated, or other areas where the range of input parameters is similar to the calibrated region.

\section{Acknowledgements}

Sainath Aher is sincerely thankful to the School of Hydro-Informatics Engineering, National Institute of Technology, Agartala (Tripura) for providing access to their research facilities during Summer Internship (May-June 2014). Further, authors wish to thank the anonymous reviewer for critically reviewing an earlier version of this manuscript and for providing helpful suggestions and comments that significantly improved its content. 


\section{Appendix}

Table A1. Parameter data for upper Dhalai watershed (66 Grids).

\begin{tabular}{|c|c|c|c|c|c|c|c|c|c|c|}
\hline Grid no. & Latitude & Longitude & $\mathrm{P}(\mathrm{cm})$ & $\mathrm{T}\left({ }^{\circ} \mathrm{C}\right)$ & $\mathrm{V}(\%)$ & $\mathrm{C}(\%)$ & $\mathrm{E}$ & S.M. (\%) & $\mathrm{CP}$ & $\mathrm{G}(\mathrm{M})$ \\
\hline A1 & 91.7703 & 24.1349 & 235 & 27 & 93.2 & 4.3 & 5.38 & 3.74 & 1 & 1.6 \\
\hline $\mathrm{A} 2$ & 91.7964 & 24.1353 & 225 & 28 & 53.1 & 41.66 & 4.54 & 3.74 & 1.5 & 1.6 \\
\hline A3 & 91.8279 & 24.1356 & 223 & 28.1 & 67.01 & 29 & 4.92 & 6.8 & 1 & 1.6 \\
\hline A4 & 91.8587 & 24.1357 & 226 & 28 & 71.23 & 20.9 & 5.04 & 7.9 & 1.5 & 1.6 \\
\hline A5 & 91.8902 & 24.1354 & 238 & 27.4 & 96.03 & 2.2 & 5 & 8.12 & 1 & 2.1 \\
\hline A 6 & 91.9222 & 24.1370 & 244 & 27.7 & 97.05 & 1.1 & 4.83 & 8.12 & 1 & 2.1 \\
\hline B1 & 91.9216 & 24.1105 & 241 & 27.7 & 94.91 & 2.1 & 5.24 & 8.4 & 1.5 & 2.1 \\
\hline $\mathrm{B} 2$ & 91.8905 & 24.1109 & 256 & 27 & 95.1 & 1.9 & 4.4 & 8.4 & 1.5 & 2.1 \\
\hline B3 & 91.8590 & 24.1110 & 227 & 27.9 & 72 & 23.11 & 4.9 & 8.8 & 2 & 2.1 \\
\hline B4 & 91.8276 & 24.1109 & 221 & 28 & 47.98 & 48.32 & 4.85 & 8.7 & 2 & 2.1 \\
\hline B5 & 91.7963 & 24.1099 & 225 & 28 & 63.4 & 32.18 & 4.9 & 5.3 & 2 & 1.6 \\
\hline B6 & 91.7674 & 24.1098 & 238 & 27.8 & 98.03 & 1 & 4.96 & 5.3 & 1.5 & 1.6 \\
\hline $\mathrm{C} 1$ & 91.7674 & 24.0797 & 241 & 27.7 & 98.9 & 0.2 & 4.95 & 5.7 & 2 & 1.9 \\
\hline $\mathrm{C} 2$ & 91.7965 & 24.0795 & 224 & 27.9 & 69.09 & 26.67 & 4.92 & 5.7 & 2 & 1.9 \\
\hline C3 & 91.8284 & 24.0790 & 222 & 28 & 44.98 & 51.9 & 5.02 & 7.55 & 2.5 & 2.3 \\
\hline $\mathrm{C} 4$ & 91.8594 & 24.0792 & 229 & 27.8 & 73.01 & 19.99 & 5.21 & 9.15 & 2 & 2.6 \\
\hline C5 & 91.8903 & 24.0797 & 243 & 26.9 & 99.02 & 0.1 & 4.82 & 7.9 & 2 & 2.6 \\
\hline C6 & 91.9220 & 24.0793 & 240 & 27.9 & 89 & 3.12 & 4.9 & 7.9 & 2 & 2.6 \\
\hline D1 & 91.9224 & 24.0484 & 237 & 27.6 & 93.83 & 5.01 & 4.69 & 6.08 & 2 & 3.1 \\
\hline D2 & 91.8906 & 24.0481 & 251 & 27.3 & 99.04 & 0.02 & 4.92 & 6.08 & 2.5 & 3.1 \\
\hline D3 & 91.8591 & 24.0484 & 227 & 27.8 & 75.09 & 19.26 & 4.99 & 4.9 & 3 & 3.1 \\
\hline D4 & 91.8276 & 24.0484 & 223 & 28 & 51.66 & 44.33 & 5.03 & 5.9 & 2.5 & 3.05 \\
\hline D5 & 91.7963 & 24.0482 & 227 & 27.9 & 86.7 & 9.23 & 5 & 5.08 & 3 & 2.5 \\
\hline D6 & 91.7661 & 24.0481 & 255 & 27.6 & 98.8 & 1.01 & 4.98 & 5.08 & 2.5 & 2.6 \\
\hline E1 & 91.7661 & 24.0168 & 257 & 27.5 & 98.69 & 0.9 & 5.07 & 4.2 & 3 & 2.3 \\
\hline $\mathrm{E} 2$ & 91.7976 & 24.0171 & 227 & 27.9 & 79.9 & 15.12 & 4.29 & 4.2 & 3 & 2.3 \\
\hline E3 & 91.8284 & 24.0171 & 227 & 27.9 & 64.09 & 31 & 5.02 & 4.1 & 3 & 3 \\
\hline $\mathrm{E} 4$ & 91.8587 & 24.0173 & 230 & 27.7 & 81.22 & 12.22 & 4.73 & 4.2 & 3.5 & 3.1 \\
\hline E5 & 91.8907 & 24.0169 & 251 & 27.1 & 96.45 & 2.99 & 5.19 & 4.9 & 2 & 3.1 \\
\hline E6 & 91.9216 & 24.0171 & 235 & 27.8 & 93.67 & 3.77 & 4.89 & 4.9 & 3 & 3.1 \\
\hline F1 & 91.9217 & 23.9854 & 242 & 27.6 & 98 & 1.3 & 4.8 & 4.7 & 3.5 & 3 \\
\hline $\mathrm{F} 2$ & 91.8903 & 23.9856 & 241 & 27.9 & 96.9 & 1.2 & 5.38 & 4.7 & 3.5 & 3 \\
\hline F3 & 91.8585 & 23.9858 & 228 & 27.9 & 59.71 & 32.11 & 4.54 & 3.7 & 3 & 3 \\
\hline $\mathrm{F} 4$ & 91.8279 & 23.9857 & 224 & 27.9 & 51.1 & 40.05 & 4.92 & 4.1 & 3.5 & 2.5 \\
\hline F5 & 91.7964 & 23.9858 & 227 & 27.9 & 77.89 & 18.03 & 5.04 & 3.7 & 4 & 2.1 \\
\hline F6 & 91.7666 & 23.9861 & 248 & 27.5 & 97.03 & 1.2 & 5 & 3.7 & 4 & 2.1 \\
\hline G1 & 91.7666 & 23.9548 & 272 & 27.4 & 98.01 & 1.09 & 4.83 & 3.4 & 3.5 & 1.8 \\
\hline G2 & 91.7967 & 23.9555 & 230 & 27.9 & 94.3 & 8.9 & 5.24 & 3.4 & 4 & 1.8 \\
\hline G3 & 91.8283 & 23.9551 & 225 & 27.9 & 39.81 & 54.07 & 4.4 & 5 & 4 & 2 \\
\hline G4 & 91.8598 & 23.9546 & 229 & 27.8 & 73.05 & 12.9 & 4.9 & 5.8 & 3.5 & 2.4 \\
\hline G5 & 91.8908 & 23.9541 & 238 & 27.6 & 92.1 & 4.11 & 4.85 & 5.2 & 4 & 2.4 \\
\hline G6 & 91.9219 & 23.9540 & 258 & 27.5 & 97.9 & 0.3 & 4.9 & 5.2 & 4.5 & 2.4 \\
\hline H1 & 91.9218 & 23.9235 & 254 & 27 & 98.1 & 1.2 & 4.96 & 5 & 4 & 1.4 \\
\hline $\mathrm{H} 2$ & 91.8903 & 23.9235 & 235 & 27.7 & 92.98 & 4.12 & 4.95 & 5 & 4.5 & 1.4 \\
\hline H3 & 91.8584 & 23.9228 & 229 & 27.8 & 66.19 & 28.02 & 4.92 & 6 & 4.5 & 1.04 \\
\hline $\mathrm{H} 4$ & 91.8277 & 23.9230 & 231 & 27.9 & 61.05 & 32.98 & 5.02 & 4.4 & 4 & 1.3 \\
\hline H5 & 91.7972 & 23.9232 & 236 & 27.7 & 97.4 & 1.9 & 5.21 & 2.45 & 4.5 & 1.6 \\
\hline H6 & 91.7656 & 23.9231 & 272 & 27.4 & 97.8 & 0.8 & 4.82 & 2.45 & 4.5 & 1.6 \\
\hline I1 & 91.7658 & 23.8915 & 254 & 27.5 & 97.97 & 0.3 & 4.9 & 2.4 & 4 & 1.6 \\
\hline I2 & 91.7976 & 23.8915 & 237 & 27.5 & 95.12 & 2.5 & 4.69 & 2.4 & 4.5 & 1.4 \\
\hline I3 & 91.8287 & 23.8922 & 231 & 27.7 & 86.7 & 9.8 & 4.92 & 4.4 & 4.5 & 1.3 \\
\hline $\mathrm{I} 4$ & 91.8599 & 23.8920 & 235 & 27.7 & 85.29 & 7.9 & 4.99 & 6 & 4 & 1.5 \\
\hline I5 & 91.8912 & 23.8918 & 239 & 27.6 & 87 & 11.29 & 5.03 & 5 & 4.5 & 1.5 \\
\hline I6 & 91.9215 & 23.8919 & 249 & 26.9 & 98.05 & 0.4 & 5 & 5 & 4.5 & 1.5 \\
\hline
\end{tabular}


Table A1. (Continued).

\begin{tabular}{lllllllllll}
\hline Grid no. & Latitude & Longitude & $\mathrm{P}(\mathrm{cm})$ & $\mathrm{T}\left({ }^{\circ} \mathrm{C}\right)$ & $\mathrm{V}(\%)$ & $\mathrm{C}(\%)$ & $\mathrm{E}$ & $\mathrm{S} . \mathrm{M} .(\%)$ & $\mathrm{CP}$ & $\mathrm{G}(\mathrm{M})$ \\
\hline J1 & 91.9218 & 23.8595 & 246 & 27.4 & 96.5 & 1.1 & 4.98 & 5 & 4.5 & 1.5 \\
J2 & 91.8903 & 23.8610 & 237 & 27.5 & 93.9 & 4.1 & 5.07 & 5 & 5 \\
J3 & 91.8601 & 23.8607 & 235 & 27.6 & 89.09 & 7.91 & 4.29 & 6 & 1.5 \\
J4 & 91.8279 & 23.8611 & 234 & 27.6 & 88.5 & 7.34 & 5.02 & 6 & 5 \\
J5 & 91.7968 & 23.8603 & 234 & 27.7 & 85.11 & 12.23 & 4.73 & 2.4 & 5 \\
J6 & 91.7646 & 23.8605 & 253 & 27.5 & 97.8 & 1.1 & 5.19 & 2.4 & 5.5 & 1.5 \\
K1 & 91.7664 & 23.8284 & 231 & 27.7 & 96.46 & 2.7 & 4.89 & 2.4 & 4.5 \\
K2 & 91.7970 & 23.8291 & 231 & 27.8 & 97.1 & 1.05 & 4.8 & 2.4 & 5 \\
K3 & 91.8291 & 23.8296 & 231 & 27.7 & 97.98 & 1.9 & 5.38 & 6 & 1.6 & 5.5 \\
K4 & 91.8576 & 23.8307 & 239 & 27.6 & 96.93 & 1.01 & 4.54 & 6 & 5 \\
K5 & 91.8928 & 23.8295 & 243 & 27.5 & 92.71 & 5.02 & 4.92 & 5 & 1.3 \\
K6 & 91.9223 & 23.8294 & 246 & 27.4 & 96.92 & 2.1 & 5.04 & 5 & 4 & 1.4 \\
\hline
\end{tabular}

\section{References}

Aher S P and Dalvi S N 2012 Remote sensing technique for monitoring the glacier retreating process and climatic changes study; Ind. Streams Res. J. 2(8) 2-6.

Aher S P, Khemnar S B and Shinde S D 2014 Synthetic aperture radar in Indian remote sensing; Int. J. Appl. Inf. Syst. 7(2) 31-34.

Dawson C W and Wilby R L 2001 Hydrological modeling using artificial neural network; Prog. Phys. Geogr. 25(1) 80-108.

Desalegn C E and Babel M S 2011 Application of ANNbased stream flow forecasting model for agricultural water management in the Awash River Basin, Ethiopia; Water Resour. Manag. 25(6) 1759-1773.

Deshmukh K K and Aher S P 2014 Particle size analysis of soils and its interpolation using GIS technique from Sangamner area, Maharashtra, India; Int. Res. J. Env. Sci. 3(10) 32-37.

Deshmukh K K and Aher S P 2016a Assessment of the impact of municipal solid waste on groundwater quality near the Sangamner City using GIS approach; Water Resour. Manag. 30(7) 2425-2443.

Deshmukh K K and Aher S P 2016b Impact of land-use changes on groundwater quality from Sangamner area, Maharashtra, India; Crystallizing ideas - The role of Chemistry, Chapter 14, Springer International Publishing, pp. 209-226.

Dracup J A, Fee K S and Paulson E G Jr 1980 On definitions of droughts; Water Resour. Res. 16(2) 297-302.

Evangelos T and Stuart H M 1995 Using the analytic hierarchy process for decision making in engineering applications: Some challenges; Int. J. Ind. Eng. Theory Appl. Pract. 2(1) 35-44.

Ghosh K, De S K, Bandyopadhyay and Saha S 2013 Assessment of soil loss of the Dhalai river basin, Tripura, India using USLE; Int. J. Geosci. 4 11-23.

Hsu K, Gupta H V and Sorooshian S 1995 Artificial neural network modeling of the rainfall runoff process; Water Resour. Res. 31(10) 2517-2530.

IRRI 2016 Tripura farmers welcome the release of droughttolerant rice varieties; International Rice Research Institute (IRRI), http://strasa.irri.org/news-and-events/ tripurafarmerswelcomethereleaseofdrought-tolerantricevarieties, 10 September, 2016.

Jain S K, Keshri R, Goswami A, Sarkar A and Chaudhry A 2009 Identification of drought vulnerable areas using
NOAA AVHRR data; Int. J. Remote Sens. 30(10) 2653-2654.

Kendale B M 2012 Rainfall and drought; Chapter 2, pp. $36-37$.

Kogan F 2008 How drought looks from space; Geocarto. Int. 10(1) 51-52.

Kumar C P 2012 Climate change and its impact on groundwater resources; Int. J. Eng. Sci. 1(5) 43-60.

McCulloch W S and Pitts W 1943 A logical calculus of the ideas imminent in nervous activity; Bull. Math. Biophys. 5 115-133.

McKee T B N, Doesken J and Kleist J 1993 The relationship of drought frequency and duration to time scales; In: Proceedings of the 8th Conference on Applied Climatology; Boston, MA, USA, Am. Meteor. Soc. 17(22) 179-184.

Palmer W C 1965 Meteorological drought, Research Paper No. 45, U.S. Weather Bureau, NOAA Library and Information Services Division, Washington, D.C. 20852.

Parida B R, Collado W B, Borah R, Hazarika M K and Samarakoon L 2013 Detecting drought-prone areas of rice agriculture using a MODIS-derived soil moisture index; GI Sci. Remote Sens. 45(1) 109-129.

Riad S and Mania J 2004 Rainfall-runoff model using an artificial neural network approach; Math. Comput. Model. 40 839-846.

Saaty T L 1980 The Analytic Hierarchy Process; McGrawHill, New York, NY.

Saaty T L 1996 Decision making with dependence and feedback, The Analytic Network Process; RWS Publications, Pittsburgh.

Saaty T L and Peniwati K 2013 Group decision making: Drawing out and reconciling differences; RWS Publications (ebook edn), pp. 35-48.

Salas J D, Delleur J W, Yevjevich V and Lane W L 1985 Applied modeling of hydrologic time series; Water Resources Publications.

SER 2002 State environmental report; Tripura, India, pp. $7-16$.

Shewale M P and Kumar S 2005 Climatological features of drought incidences in India; Meteorological Monograph Climatology, National Climate Centre, Indian Meteorological Department, pp. 2-7.

Van Loon A F, Tijdeman E, Wanders N, Van Lanen H, Teuling A J and Uijlenhoet R 2014 How climate seasonality modifies drought duration and deficit; J. Geophys. Res. D Atmos. 119(8) 4640-4656.

Wan Z, Wang P and Li X 2004 Using MODIS land surface temperature and normalized difference vegetation index 
products for monitoring drought in the southern Great Plains, USA; Int. J. Remote Sens. 25(1) 61-72.

Zhao M and Running S W 2010 Drought-induced reduction in global terrestrial net primary production from 2000 through 2009; Science 329(5994) 940-943.

Zolekar R B and Bhagat V S 2015 Multi-criteria land suitability analysis for agriculture in hilly zone: Remote sensing and GIS approach; Comp. Electron. Agri. 118 300-321.

Yang C L, Chuang S P, Huang $\mathrm{R} \mathrm{H}$ and Tai C C 2008 Location selection based on AHP/ANP approach; IEEE, International Conference on Industrial Engineering and Engineering Management, Singapore, pp. 11481153 .

MS received 11 July 2016; revised 12 October 2016; accepted 8 November 2016

Corresponding editor: RAJIB MAITY 